\title{
Developmental Origins of Disease
}

\section{P D Gupta*}

Former Director Grade Scientist, Centre for Cellular and Molecular Biology, Hyderabad, India

Correspondence to: PD Gupta, Former Director Grade Scientist, Centre for Cellular and Molecular Biology, Hyderabad, India; E-mail: pdg2000@hotmail.com Received date: July1, 2020; Accepted date: July12, 2020; Published date: July19, 2020

Citation: PD Gupta(2020) Developmental origins of disease. J Obst Gynecol Surg. 1(1): pp. 1-3.

Copyright: (02020Gupta PD. This is an open-access article distributed under the terms of the Creative Commons Attribution License, which permits unrestricted use, distribution and reproduction in any medium, provided the original author and source are credited.

\section{ABSTRACT}

At any age one can become sick, however, it is pathetic when someone is born with a disease that too which is not expressed immediately. Such diseases show up weeks later and some years later. The causes of such diseases are multifactorial. In this mini-review, we are trying to focus on some important risk factors which should be considered before getting pregnant; in some genetic disorders, genetic analysis is important, even before pregnancy, for others prenatal diagnosis is recommended.

\section{Keywords:}

Disease, Blood, Birth, Pregnancy, Vital organs.

\section{Introduction}

Food is essential for every living being from birth to death. Food provides nourishment for growth and energy to work. If there is a misbalance in food intake (both, quality and quantity) we get diseases. The food a pregnant woman takes during pregnancy plays a prime role in well being of that particular individual throughout his/her life [1,2] Dutch-led team of researchers examined blood samples obtained from individuals whose mothers were pregnant with them during the Dutch Hunger Winter of 1944 to 1945, toward the end of World War II, and from their siblings who were born either before the six-month famine or after and found that the individuals exposed to famine in utero had particular methylation of the gene (PIM3). The individuals whose mothers were pregnant during the famine have been shown to have higher rates of obesity, dyslipidemia, diabetes, and schizophrenia. Maybe their metabolism is in a lower gear [3]. Tobi et al.suggest that PIM3 was silenced in the fetuses in response to the starvation faced by their mothers and then never reactivated [4]. Excessive exposure to glucocorticoids (stress hormones) are well known for their role in homeostasis (control of blood pressure and glucose metabolism) in adult life but are also essential for fetal maturation [5].

\section{Causative factors}

Now it has become clear that many diseases have origins during development. This may have multifactorial reasons such as, altered nutrition, as well as exposure to environmental chemicals, drugs, infections, or stress during specific times of development that can lead to functional changes in tissues, predisposing those tissues to diseases that manifest later in life [6]. Diseases may appear at any time in life, however recent studies show the different groups of which are called 'Fetal Origins of Adult Disease' disease a rather more recent term for the concept initially proposed in the 1990s [7].By using approaches that address the influence of environmental factors on growth and development even during embryonic stage longterm health outcomes can be forecasted [8].

\section{Genetics and Metabolism}

It is a fact that some mutated genes carrying by the parents can cause or contribute to various types of metabolic disorders or structural deformity in the foetuses $[9,10]$.The symptoms of such diseases can show up within a few weeks after birth.In some cases, these symptoms expressed even after adulthood. A detailed account has been mentioned in the two books mentioned above $[9,10]$.

The defective genes may either inherited or change their expression due to exposure to certain environmental influences during critical periods of development and growth may have significant consequences on an individual's short- and long-term health [11].In this concept, the developing fetus, if exposed to a hostile uterine environment [caused by insults such as poor nutrition, infections, chemicals, metabolite or hormonal perturbations), responds by developing adaptations[predictive adaptive responses PARs), that not only foster its immediate viability, but also its survival if a similar environment is encountered later in life [12-15]. Some examples of short-term adaptations the fetus may make in these scenarios include down-regulation of endocrine or metabolic function, and/or specific organ function to slow down its growth rate to match the nutrient supply in the deprived uterine environment. Long-term, subtle, irreversible changes in the development, structure, and function of some tissues and vital organs (Thymus, skeletal muscle, lungs, pancreas, kidney) may occur as a result of disruptions in gene expression, cell differentiation, and proliferation [11]. However, if the individual then grows up in an extra-uterine environment the reverse of that experienced in utero, the 'mismatch' and poorer fit, therefore, would predispose them to a higher risk of certain non-communicable diseases [16].This risk is further exacerbated by excessive weight gain in postnatal/adult life, and by the aging process itself [16].

\section{Placenta}

The placenta, a transitory organ, forms when cells from a fertilized egg secure a beachhead in the uterine lining. Ninety percent of the placenta is made up of cells, not from the mother but from the fetus. Theplacenta is essential for supporting the baby as it grows inside the mother. By week 12 of pregnancy, the placenta has all the structures it needs to step in for the corpus luteum and sustain the growing baby for the rest of pregnancy: although it will continue to grow larger as your baby grows. It is dismissed literally, to the trash bin after the child's birth. But at long last, it is beginning to get its due [17].The placenta produces severalhormones that are needed during pregnancy, such as, 
lactogen, oestrogen, and progesterone [18]. These hormones play an important role in both mother and child's physiological processes[18,19]. The fetus is connected to the placenta by a tube called the umbilical cord. The cord blood has been used to treat children with certain blood diseases since 1989 and research on using it to treat adults is making progress. The cord contains two arteries and a vein. Substances pass back and forth between the mother's and fetus's blood through the placenta and cord [20,21]. When it doesn't function properly, it can result in serious problems, from pre-eclampsia to miscarriage, with immediate and lifelong consequences for both mother and child[22-24]. But our knowledge of this important organ is very limited because of a lack of good experimental models. Placental trophoblast cells combined with the organoid culture system enabled the generation of miniature functional models of the early placenta or mini-placentas [25]. In the past few years, a new field of research has developed that uses these organoids, enabling insights into human health and disease. These trophoblastorganoidscan survive long-term due to their characteristic properties $[25,26]$, are genetically stable, and organize into villous-like structures that secrete essential proteins and hormones that would affect the mother's metabolism during the pregnancy. The Mini-placentas' could provide a model for early pregnancy. Researchers say that new mini-placentas a cellular model of the early stages of the placenta could provide a window into early pregnancy and help transform our understanding of reproductive disorders [25].

\section{Epigenetics}

Understanding the mechanism of epigenetic resetting could be exploited to deal with adult diseases such as cancers, or in 'rejuvenating' aged cells, linked with an accumulation of aberrant epigenetic marks. The significance of the information would also depart from well known and generally accepted environmental effects on the unborn fetus in the mother's womb or other maternal effects, mediated by the many provisions in the zygote during embryogenesis, and after birth, through mother's milk [27]. Also, in-depth understanding provides vital information to find how to erase aberrant epigenetic marks that may underlie some diseases in adults and also provide opportunities to address whether germ cells can acquire new epigenetic marks through environmental or dietary influences on parents that may escape erasure and be transmitted to subsequent generations, with potentially undesirable consequences [28].

\section{Microbiota}

Pregnancy induces several immunological, hormonal, and metabolic changes necessary for the normal development of the fetus and for the timely onset of labor and successful delivery. The rise in estrogensandprogesterone during pregnancy alters gut function and microbiotacomposition, increasing vulnerability to pathogens. The gut microbiotaprogressively changes with each trimester of pregnancy; the composition is most commonly dominated by Firmicutes as in obese populations. The concept of embryonic development in a sterile uterus has been challenged and now the existence of microbiota of the placenta, amniotic fluid, and the fetal gut is considered in normal, uncomplicated pregnancies. The maternal microbiota is recognized as a key determinant of a range of important maternal and child health outcomes, and together with perinatal factors influences the infant microbiota[29].

\section{Food and Drinks}

For a healthy pregnancy and childbirth, the mother's diet needs to be balanced and nutritious. Since calorie and nutrient needs are increased, it is very important that during pregnancy choose nutrient-dense, fiber-rich healthy foods should be consumed. In a recent study, it is shown that composition of gut microbiota changes in pregnant women, and the changing microbial environment needs to be changed die to keep a proper balance between beneficial and harmful bacteria [30].

Blood volume has to be increased; therefore the system absorbs iron more efficiently, so she has to consume more iron to make sure that both she and her baby have an adequate oxygen supply. This benefits the growing baby also. Gaining weight during pregnancy is normal, but it is important to gain the healthy way.

Too much exposure to alcohol and caffeine can seriously undermine the baby's development. One should limit the intake of these. Now it is well established that diet before birth modifies gene expression and therefore healthy diet results in getting a healthy baby [31].

Conflict of Interest: There are no conflicts of interest.

\section{References}

1. Gupta PD (2019) You are what Your Mother Ate: Role of Dietary Fibers. Arch Reprod Med Sexual Health 2(1): pp. 30-34.

2. Gupta PD, Ballal HS (2012) Childhood Cancer, Manipal University Press, Manipal, India.

3. Hart N (1993) Famine, Maternal Nutrition and Infant Mortality: A Re-Examination of the Dutch Hunger Winter. Popul Stud 47(1): pp. 27-46.

4. Tobi EW, Slieker RC, Luijk R, et al. (2018) DNA methylation as a mediator of the association between prenatal adversity and risk factors for metabolic disease in adulthood. Science Advances 4(1): pp. eaao4364.

5. Nyirenda MJ, Lindsay RS, Kenyon CJ, et al. (1998) Glucocorticoid exposure in late gestation permanently programs rat hepatic phosphoenolpyruvate carboxykinase and glucocorticoid receptor expression and causes glucose intolerance in adult offspring. J Clin Invest 101(10): pp. 2174-2181.

6. Heindel JJ, Vandenberg LN (2015) Developmental Origins of Health and Disease: A Paradigm for Understanding Disease Etiology and Prevention Curr Opin Pediatr 27(2): pp. 248-253.

7. Hales CN, Barker DJ, Clark PM, et al. (1991) Fetal and infant growth and impaired glucose tolerance at age 64. Br Med J 303(6809): pp. 1019-1022.

8. Mandy M, Nyirenda M (2018) Developmental Origins of Health and Disease: the relevance to developing nations. Int Health 10(2): pp. 66-70.

9. Gupta PD, Srivastava LM (2015) Essentials of Inborn Metabolic and Genetic Disorders. Pug Publications Pvt Ltd, Chennai, India.

10. Gupta PD. Manageable Genetic and metabolic Disorders. Pug Publications Pvt Ltd, Chennai, India.

11. Schoenfelder S, Fraser P (2019) Long-range enhancerpromoter contacts in gene expression control. Nat Rev Genet 20: pp. 437-455.

12. Silver KL, Singer PA (2014) A focus on child development. Science 345(6193): pp. 121. 
13. Kinsella MT, Catherine M (2009) Monk Impact of Maternal Stress, Depression \& Anxiety on Fetal Neurobehavioral Development Clin Obstet Gynecol 52(3): pp. 425-440.

14. Gluckmana PD, Hansonb MA, Spencer HG (2005) Predictive adaptive responses and human evolution. Trends Ecol Evol 20(10): pp. 527-533.

15. Stevens CF (2015) Control of organ size: development, regeneration, and the role of theory in biology. BMC Biol 13: pp. 14.

16. Peters R, Ee N, Peters J, et al. (2019) Common risk factors for major noncommunicable disease, a systematic overview of reviews and commentary: the implied potential for targeted risk reduction. Ther Adv Chronic Dis. 10.

17. https://parentsguidecordblood.org/en/news/what-yourplacenta-can-and-cant-do, 2020

18. Costa MA (2016) The endocrine function of human placenta: an overview. Reprod Biomed Online 32(1): pp. 14-43.

19. Napso T, Yong HEJ, Lopez-Tello J, et al. (2018) The Role of Placental Hormones in Mediating Maternal Adaptations to Support Pregnancy and Lactation. Front Physiol 9: pp. 1091.

20. Spurway J, Logan P, Pak S (2012) The development, structure and blood flow within the umbilical cord with particular reference to the venous system. Australas J Ultrasound Med 15(3): pp. 97-102.

21. Ferguson VL, Dodson RB (2009) Bioengineering Aspects of the Umbilical Cord. Eur J Obstet Gynecol Reprod Biol 144 Suppl 1: pp. S108-S113.

22. Jauniaux E, Poston L, Burton GJ (2006) Placental-related diseases of pregnancy: involvement of oxidative stress and implications in human evolution. Hum Reprod Update 12(6): pp. 747-755.

23. Roberts JM, Escudero C (2012) The placenta in preeclampsia. Pregnancy Hypertens 2(2): pp. 72-83.

24. Mifsud W, Sebire NJ (2014) Placental Pathology in EarlyOnset and Late-Onset Fetal Growth Restriction Fetal Diagn Ther 36(2): pp. 117-128.

25. University of Cambridge (2018) 'Mini-placentas' could provide a model for early pregnancy. Science Daily.

26. Paul S, Gupta PD, Jailkhani BL, et al. (1980) Resistance of Human Syncytiotrophoblast to Hypotonic and Thermal Stress. J Reprod Fertil 58(1): pp. 183-187.

27. Gupta PD (2010) Mothering a Cause. Capricorn Publishing House, Jaipur, India.

28. Pushkala K, Gupta PD (2013) Epigenetic Effect of Food for Cancer Management. Int J Med Sciences and Biotechnology 1: pp. 1-11.

29. Edwards SM, Cunningham SA, Dunlop AL, et al. (2017) The Maternal Gut Microbiome during Pregnancy. MCN Am J Matern Child Nurs 42(6): pp. 310-317.

30. Schoenmakers S, Steegers-Theunissen R, Faas M (2019) The matter of the reproductive microbiome. Obstet Med 12(3): pp. 107-115.

31. Weathersbee PS, Lodge JR (1979) Alcohol, Caffeine, and Nicotine as Factors in Pregnancy. Postgrad Med 66(3): pp. 165$167,170-171$. 